\title{
Hypertrophic cardiomyopathy: Interactive 3-dimensional modeling of phenotypic variants
}

\author{
Meher Oberoi, MBBS, ${ }^{\mathrm{a}}$ Thomas A. Foley, MD, ${ }^{\mathrm{b}}$ and Hartzell V. Schaff, MD ${ }^{\mathrm{a}}$
}

Supplemental material is available online.

Hypertrophic cardiomyopathy with left ventricular outflow tract obstruction due to basal septal thickening is the most common morphology encountered by surgeons. ${ }^{1}$ There are, however, other phenotypic variants amenable to surgical treatment, and recognition of these guides the operative approach. ${ }^{2}$ For instance, patients with an isolated subaortic obstruction (Figure 1, Al and $A 2$ ) will benefit from a transaortic extended septal myectomy alone, whereas patients with the complex long segment subaortic phenotype (Figure 1, B1 and $B 2$ ) will likely require additional transventricular myectomy to adequately relieve obstruction.

To better visualize, understand, and classify the hypertrophic cardiomyopathy phenotypes of surgical importance, we created 3-dimensional (3D) reconstructions of 4 hearts (in systole and diastole) from multiphasic cardiac computed tomographic images (Figure 2). These images were obtained preoperatively in patients who subsequently underwent surgical myectomy. Materialise Mimics software (Materialise $\mathrm{NV}$, Leuven, Belgium) was used to segment the left heart blood pool, the right heart blood pool, and the myocardium. We then used Materialise 3-Matic (Materialise NV) software to create completed 3D models of the heart. These models were then sectioned and exported as interactive 3D PDF files that may be downloaded (see Appendix E1 and Online Data Supplements 1-4). Key anatomic features are described.

\footnotetext{
From the Departments of ${ }^{\mathrm{a} C}$ ardiovascular Surgery and ${ }^{\mathrm{b}}$ Radiology, Mayo Clinic, Rochester, Minn.

Supported by the Paul and Ruby Tsai Family.

Disclosures: The authors reported no conflicts of interest.

The Journal policy requires editors and reviewers to disclose conflicts of interest and to decline handling or reviewing manuscripts for which they may have a conflict of interest. The editors and reviewers of this article have no conflicts of interest.

Received for publication Nov 10, 2020; revisions received Dec 15, 2020; accepted for publication Dec 24, 2020; available ahead of print Jan 12, 2021.

Address for reprints: Hartzell V. Schaff, MD, Department of Radiology, Mayo Clinic, 200 First St, SW, Rochester, MN 55905 (E-mail: schaff@mayo.edu).

J Thorac Cardiovasc Surg 2022;163:e243-5

$0022-5223 / \$ 36.00$

Copyright (c) 2021 by The American Association for Thoracic Surgery

https://doi.org/10.1016/j.jtcvs.2020.12.118
}

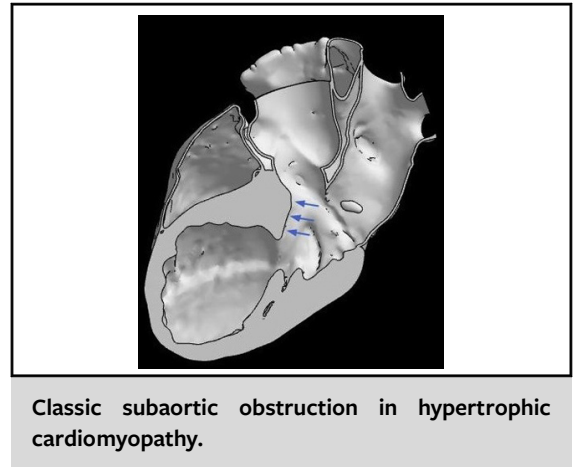

\section{CENTRAL MESSAGE \\ 3D heart models created from \\ CT imaging show 4 phenotypic variants of hypertrophic cardiomyopathy.}

See Commentaries on pages e247 and e248.

The authors thank the Anatomic Modeling Unit at Mayo Clinic (Rochester, Minn) for providing support for this work.

\section{References}

1. Maron MS, Maron BJ, Harrigan C, Buros J, Gibson CM, Olivotto I, et al Hypertrophic cardiomyopathy phenotype revisited after 50 years with cardiovascular magnetic resonance. J Am Coll Cardiol. 2009;543:220-8.

2. Nguyen A, Schaff HV. Surgical myectomy: subaortic, midventricular, and apical Cardiol Clin. 2019;37:95-104. 

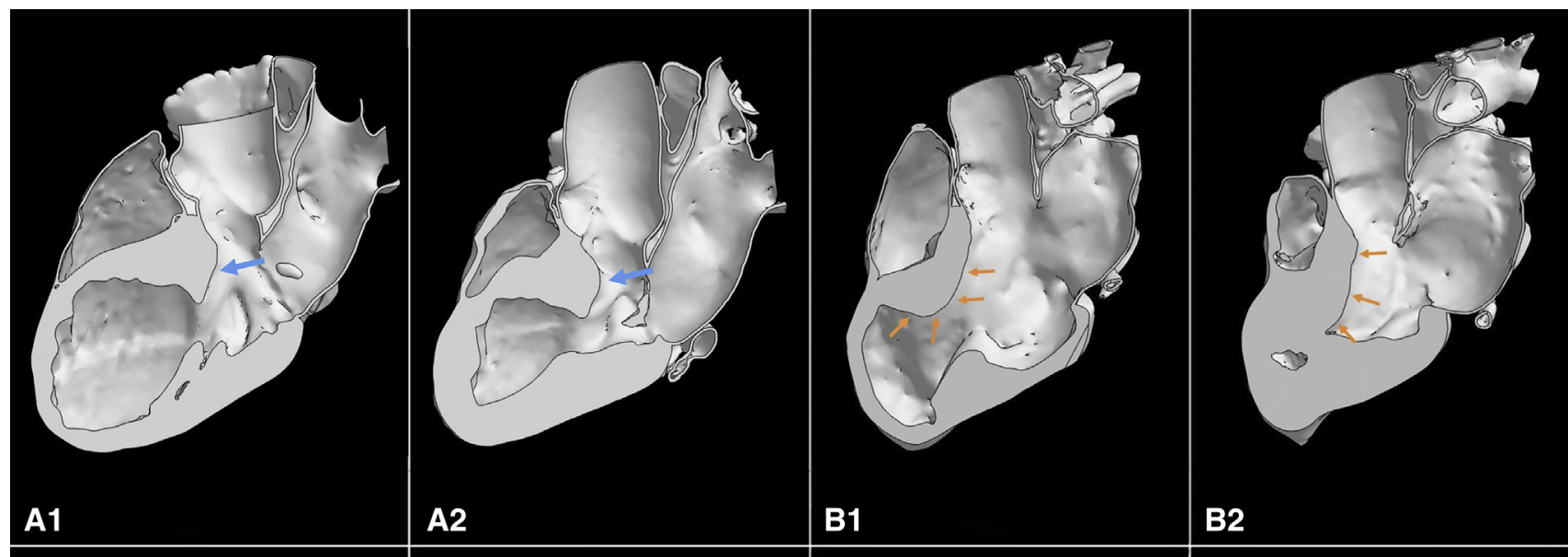

A2

\section{B1}
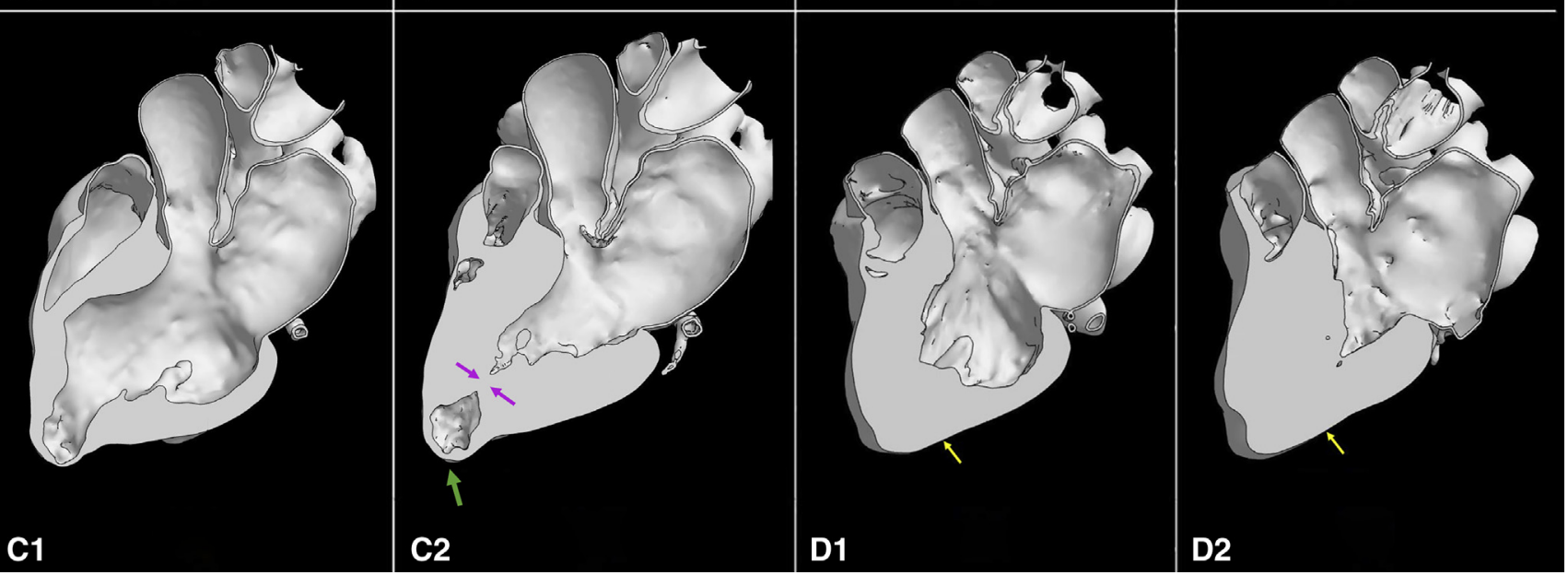

C1

C2

D1

D2

FIGURE 1. Preoperative cardiac computed tomography (CT) images were segmented and computer-aided design software was used to create patient-specific 3D heart models that were then sectioned and exported as images that are included in the panels of Figure 1. A1, (diastole) and A2, (systole), A classic subaortic obstruction; a blue arrow points to the subaortic hypertrophic segment. This is the most commonly encountered morphology and can typically be adequately addressed with a transaortic septal myectomy. B1, (diastole) and B2, (systole), The long segment subaortic variant with a hypertrophic segment (orange arrows) that extends beyond the immediate subaortic area. $\mathrm{C} 1$, (diastole) and $\mathrm{C} 2$, (systole), The midventricular obstruction (pink arrows), and a green arrow indicates the apical aneurysm, a high-risk feature associated with hypertrophic cardiomyopathy. Panels D1, (diastole) and D2, (systole), an apical variant with reduced left ventricular cavity size; a yellow arrow points to the significantly increased myocardial mass in the distal one-third of the ventricle. Adequate relief of obstructive symptoms was achieved by septal myectomy in each of these cases. The subaortic case was managed by a transaortic approach, the midventricular and apical cases were managed with a transapical approach, and the long segment subaortic case was managed with a combined transaortic-transapical approach.

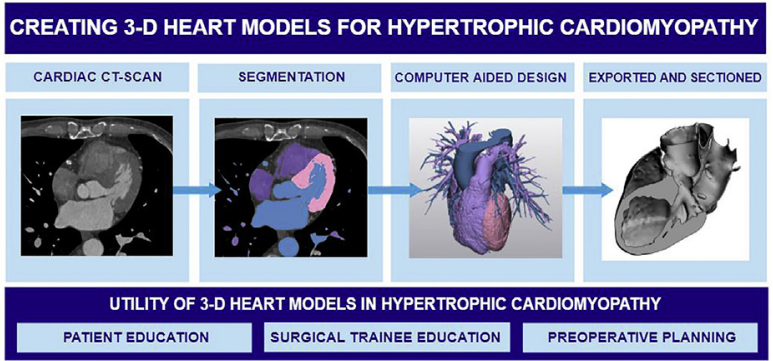

FIGURE 2. The workflow for creation of a 3-dimensional $(3 D)$ heart model. From left to right, computed tomography $(C T)$ scan images are imported into 3D modeling software. As a result, the right heart blood pool, left heart blood pool, and the myocardium are segmented separately and made into individual parts. These individual parts are then exported into computer-aided design software to create an accurate hollowed out heart model that may then be exported as an interactive PDF or printed using a 3D printer. 


\section{APPENDIX E1. HOW TO VIEW HEART MODEL PDF FILESAPPENDIX E1:}

1. Please ensure that Adobe Acrobat Pro DC is installed on your system.

2. Download the PDF, right click and open with Adobe Acrobat Pro DC. A blank sheet will appear with the following message displayed on top-" $3 \mathrm{D}$ content has been disabled. Enable this feature if you trust this document." Click on "options" and from the drop down menu, select "Trust this document one time only." If this message is not displayed, simply right-click and select enable content. You may have to wait for the content to appear.

3. Once it appears, you will be able to move the heart model by left clicking and holding while moving the mouse. You will be able to zoom in and out by right clicking and holding while moving the mouse diagonally up and out (to zoom in) and down and in (to zoom out).

4. In the left lower column, you will find the following pre-set headings:

$$
\begin{aligned}
& \text { S - transaortic } \\
& \text { D - transaortic } \\
& \text { S - } 3 \text { chamber } \\
& \text { D - } 3 \text { chamber } \\
& \text { S - short axial section } \\
& \text { D - short axial section } \\
& \text { S - whole heart }
\end{aligned}
$$

Please note that here, $\mathrm{S}$ refers to systole and $\mathrm{D}$ to diastole; 3-chamber and short axial are the planes in which the heart is sectioned. Simply click on a heading to view it. You will be able to move the model and adjust your view as described in point 3 .

5. Under the model tree (left upper column) you will find the following titles:

$$
\begin{aligned}
& \text { Model } \\
& \text { Root } \\
& \text { Parts } \\
& \text { Whole heart in systole } \\
& \text { Whole heart in diastole } \\
& \text { S - } 3 \text { chamber - } 1 \\
& \text { S - } 3 \text { chamber - } 2 \\
& \text { D - } 3 \text { chamber - } 1 \\
& \text { D - } 3 \text { chamber - } 2 \\
& \text { D - short axis - } 1 \\
& \text { D - short axis - } 2 \\
& \text { S - short axis - 1 } \\
& \text { S - short axis - } 2
\end{aligned}
$$

Please note that here, $\mathrm{S}$ refers to systole and $\mathrm{D}$ to diastole; 3 -chamber and short axis are the 2 planes in which the heart has been sectioned; the numbers -1 and -2 correspond to the 2 separate halves of a sectioned heart.

Deselect all the boxes (parts) and select a single part that you would like to see. You can also look at superimposed systolic and diastolic models by selecting corresponding parts from the model tree; for example, selecting $\underline{\mathrm{S}-3}$ chamber-1 and D-3 chamber-1 will provide a superimposed image of one half of the heart in systole and diastole sectioned in the 3-chamber plane. 